\title{
Real-Time Warning and Risk Assessment of Tailings Dam Disaster Status Based on Dynamic Hierarchy-Grey Relation Analysis
}

\author{
Wen Li, ${ }^{1}$ Yicheng Ye, ${ }^{1,2}$ Nanyan Hu $\left(\mathbb{D},{ }^{1}\right.$ Xianhua Wang, ${ }^{3}$ and Qihu Wang ${ }^{1}$ \\ ${ }^{1}$ School of Resource and Environmental Engineering, Wuhan University of Science and Technology, Wuhan 430081, Hubei, China \\ ${ }^{2}$ Industrial Safety Engineering Technology Research Center of Hubei Province, Wuhan 430081, Hubei, China \\ ${ }^{3}$ Sinosteel Wuhan Safety and Environmental Protection Research Institute Co., Ltd., Wuhan 430081, Hubei, China \\ Correspondence should be addressed to Nanyan Hu; hunanyan@aliyun.com
}

Received 14 March 2019; Accepted 9 April 2019; Published 18 April 2019

Academic Editor: Roberto Natella

Copyright (C) 2019 Wen Li et al. This is an open access article distributed under the Creative Commons Attribution License, which permits unrestricted use, distribution, and reproduction in any medium, provided the original work is properly cited.

\begin{abstract}
The consequences of tailings dam breaks are disastrous; although various factors can often result in tailings dam damage, the main cause is poor management. To reduce human supervision errors and ensure that real-time early warnings alerts are sent for any risks, 22 evaluation indexes that affect dam breaks were set up based on inherent and frequency risk. To efficiently predict an early dam break signal for a tailings dam, 12 key evaluation indexes of a dynamic early warning system were screened and a comprehensive consideration of the risk trend was undertaken. The current and future states of the 12 indexes were analyzed based on a borda count and dynamic analytic hierarchy process (AHP) methods and early warning grades for tailings dam damage were evaluated using the dynamic grey relation analysis method. The dynamic AHP method, which avoids the tedious testing and risks of static early warning states, was compared to the traditional method. This research provides a useful basis upon which mining enterprises can select reasonable and effective prediction indexes for risk assessment, fully implement and promote intelligent management of major risks, and conduct accurate and authentic supervision at all levels.
\end{abstract}

\section{Introduction}

Breakages are the most common accident faced by tailings dams [1]. The consequences of tailings dam failures are often catastrophic [2]; they can cause huge environmental and human losses, are a serious threat to the life and property of downstream residents and are a major source of environmental pollution that cause secondary disasters $[3,4]$. Therefore, it is necessary to research the early warning signs of tailings dam failure to improve safety conditions. Furthermore, given that humans sometimes intervene in warning systems and that supervision errors can sometimes occur, avoiding accidents is difficult on a fundamental level [5]. In addition, improvements in management systems and supervision have been found to have been needed in investigations of accidents [6-8]. This is why the role of enterprise leader is a very important position; their management ability determines how the enterprise develops.
Risk decision-making is uncertain because risks are themselves uncertain and dynamic $[9,10]$. The analytic hierarchy process (AHP) is a widely used quantitative and qualitative analysis method suitable for situations in which the results of decisions are difficult to measure directly and accurately (Table 1) [11-14]. However, the variables used in the AHP method are not always easily acquired. For example, verifying the consistency of AHP results requires recalculation when there are inconsistencies, as this indicates that there is not only one result relevant to the inconsistency and thus that one variable is ambiguous $[15,16]$. Although the use of the AHP in various fields has improved greatly, modifications can still be made in the following areas:

(i) The comparison of two elements; the definition of categories such as "slightly important," "more important," "very important," and "significant" are still 
TABLE 1: Comparison of different risk evaluation methods.

\begin{tabular}{|c|c|c|c|c|}
\hline No. & Method & Introduction & Advantages & Disadvantages \\
\hline 1 & $\begin{array}{c}\text { Stochastic analytical } \\
\text { hierarchy process (AHP) } \\
{[22]}\end{array}$ & $\begin{array}{l}\text { Used to calculate the weight } \\
\text { of indicators }\end{array}$ & $\begin{array}{l}\text { The decision maker can } \\
\text { choose the appropriate } \\
\text { method to rate the relative } \\
\text { importance of evaluation } \\
\text { indexes to express the } \\
\text { evaluation value according } \\
\text { to their personal } \\
\text { preferences, giving them } \\
\text { sufficient flexibility. }\end{array}$ & $\begin{array}{c}\text { A relatively large random } \\
\text { uncertainty. }\end{array}$ \\
\hline 2 & $\begin{array}{c}\text { Fuzzy comprehensive } \\
\text { analysis }\end{array}$ & $\begin{array}{l}\text { Based on mathematics, this } \\
\text { method applies the } \\
\text { principle of synthesizing } \\
\text { fuzzy relations. It quantifies } \\
\text { some factors with unclear } \\
\text { boundaries and that are } \\
\text { otherwise difficult to } \\
\text { quantify. }\end{array}$ & $\begin{array}{l}\text { Digital methods deal with } \\
\text { fuzzy evaluation objects; } \\
\text { reasonable quantitative } \\
\text { evaluation can be made } \\
\text { using ambiguous data [23]. }\end{array}$ & $\begin{array}{l}\text { Computation is complex } \\
\text { and subjectivity is high. }\end{array}$ \\
\hline 3 & Game theory (GT) & $\begin{array}{l}\text { A mathematical construct } \\
\text { that assumes a small } \\
\text { number of rational players } \\
\text { who have a limited number } \\
\text { of actions or strategies } \\
\text { available to them [24]. }\end{array}$ & $\begin{array}{l}\text { Based on the idea that the } \\
\text { two people use their own } \\
\text { strategies to change their } \\
\text { confrontation strategies in } \\
\text { an equal game to achieve } \\
\text { the goal of winning. }\end{array}$ & $\begin{array}{l}\text { Used for comparisons } \\
\text { between limited } \\
\text { participants }\end{array}$ \\
\hline 4 & $\begin{array}{l}\text { Probabilistic Neural } \\
\text { Networks (PNN) }\end{array}$ & $\begin{array}{l}\text { A kind of radial basis } \\
\text { function neural network, } \\
\text { widely used in pattern } \\
\text { classification [25]. }\end{array}$ & $\begin{array}{l}\text { The learning process is } \\
\text { simple, the training speed is } \\
\text { fast, the classification is } \\
\text { accurate, and the fault } \\
\text { tolerance is high. }\end{array}$ & $\begin{array}{l}\text { The quantitative analysis } \\
\text { requires sufficient data. }\end{array}$ \\
\hline 5 & Genetic algorithm (GA) & $\begin{array}{l}\text { An iterative stochastic } \\
\text { algorithm in which natural } \\
\text { evolution is used to model } \\
\text { the search process }[26,27] \text {. }\end{array}$ & $\begin{array}{l}\text { The evaluation process is } \\
\text { simple; the iterations are } \\
\text { performed using random } \\
\text { probability mechanisms. }\end{array}$ & $\begin{array}{l}\text { Implementation requires } \\
\text { complicated programming } \\
\text { and sufficient data. }\end{array}$ \\
\hline 6 & Risk Matrix [28] & $\begin{array}{l}\text { A qualitative risk } \\
\text { assessment and analysis } \\
\text { method that can } \\
\text { synthetically evaluate the } \\
\text { possibility of risk } \\
\text { occurrence and the severity } \\
\text { of injury. }\end{array}$ & $\begin{array}{l}\text { Generally used in the } \\
\text { absence of complete and } \\
\text { accurate historical data. }\end{array}$ & $\begin{array}{l}\text { The results of qualitative } \\
\text { analysis and prediction are } \\
\text { ambiguous. }\end{array}$ \\
\hline 7 & GRA method & $\begin{array}{l}\text { For the factors between two } \\
\text { systems, the measure of the } \\
\text { magnitude of the } \\
\text { correlation that changes } \\
\text { with time or different } \\
\text { objects is called the } \\
\text { correlation degree }[17,18] \text {. }\end{array}$ & $\begin{array}{c}\text { GRA provides a } \\
\text { quantitative measure for } \\
\text { the development and } \\
\text { change in a system, which } \\
\text { is very suitable for dynamic } \\
\text { process analysis. }\end{array}$ & $\begin{array}{l}\text { The correlation between } \\
\text { factors is ambiguous. }\end{array}$ \\
\hline
\end{tabular}

ambiguous and lead to time-consuming verifications of the cycle.

(ii) The scales that remain for the two elements when the scale value is selected, once the relationship between two elements has been determined, and the remaining fuzzy uncertainties in the selection process.

(iii) Risk trends which are not considered in the assessment and thus tend to be static. Therefore, if the outcome of the risk assessment result is positive, it represents only the current status and not the trend for future developments.

Nevertheless, the early warning status of tailings dam breaks cannot be fully interpreted using the AHP method alone. In the past few years, a variety of evaluation methods have been proposed for use in combination with AHP; the typical methods are shown in Table 1 . However, these methods have their own advantages and disadvantages and not all of them can be applied well to risk assessment. For example, the first six methods to evaluate the early warning 


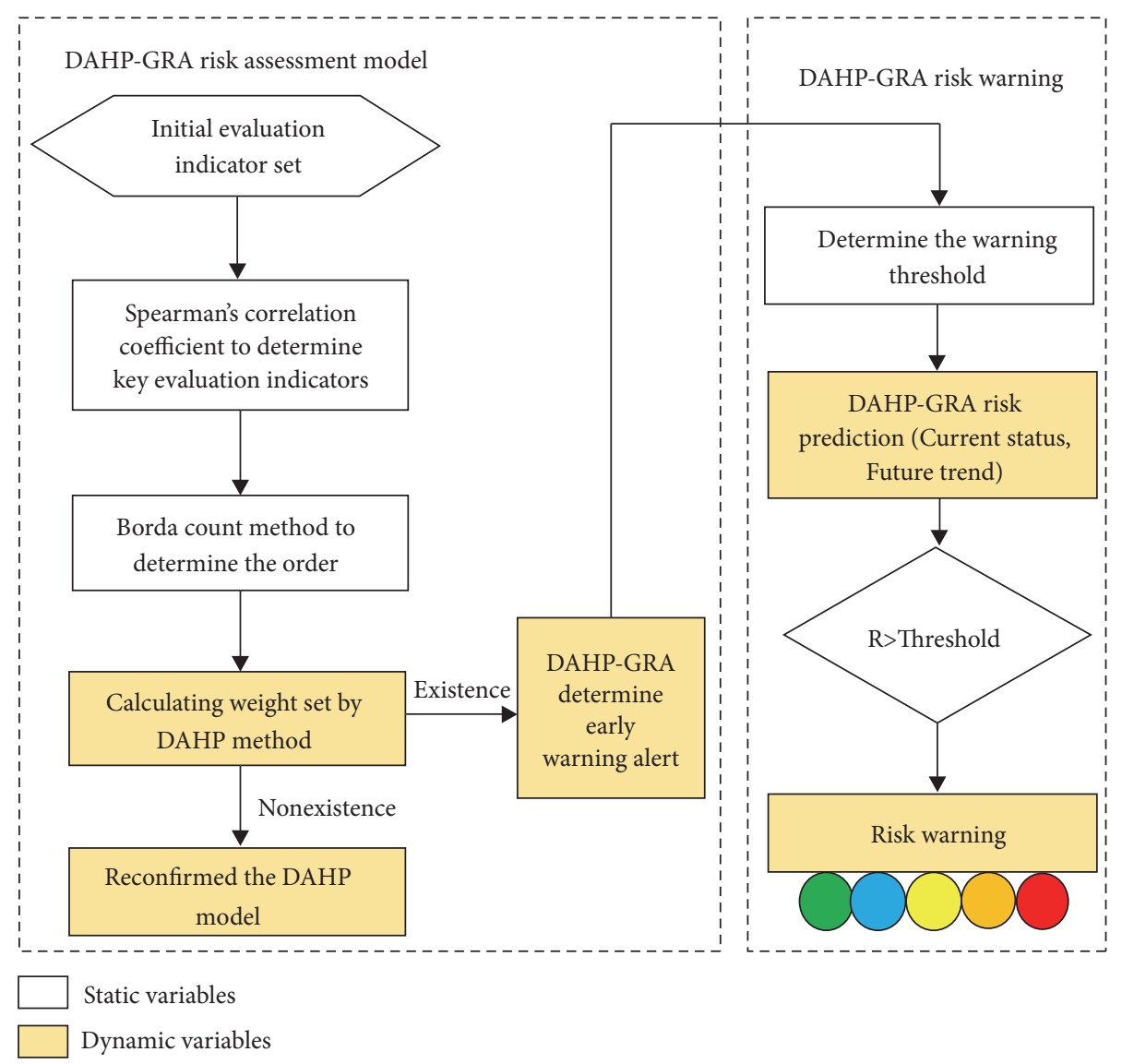

FIGURE 1: Model of the dynamic analytic hierarchy process (DAHP) and grey relational analysis (GRA) methods.

status of tailings dam are limited or static; however, grey relational analysis (GRA) can solve this problem effectively. The GRA method can use mathematics to effectively solve the lack of theoretical uncertainty information. GRA method uses less data modelling than the first six methods and has a goal of establishing differential equations, characterized by dynamic time series used for prediction and decision-making [10]. Applying the GRA method combined with the AHP can effectively overcome the problem of high correlation ambiguity. Samvedi et al. [17], Xia et al. [18], and Mathivathanan et al. [19] used GRA and AHP to enhance the reliability of predictions and overcome ambiguities in data. Most scholars select early warning indicators from human and machine inputs, the environment, and management methods. However, although these can result in good early warnings [20, 21], the evaluation indicators are static in the models used by researchers while a real-life risk status is dynamic. Therefore, characterizing the risk of uncertainty requires a consideration of the risk of bias so that the evaluation results achieve the effect of avoiding human interference in forecasting the alarm status. This provides a new direction for traditional AHP and GRA research.

In summary, combining AHP and GRA methods is a relatively widespread technique; however, there are comparatively few studies on using these to study early warnings for tailings dam hazards. Moreover, there is very little research employing dynamic state-of-the-art correlation analysis methods for tailings dam collapses. Most traditional risk analysis methods are static and fail to capture the states of risk evolution [29]. However, the consequences of tailings dam breaks are dynamic events and circumstances beyond control. Thus, it is very necessary to ensure intelligent risk management and control of the mine system as obtaining characteristic data on tailings and making use of them reduces risks of tailings dam disasters. This is similar to how violations of highway rules are managed and controlled using an information network; by obtaining data on vehicles and roads, we can judge whether a particular vehicle is legal or not. These methods could also be employed to improve the systemic risk management and control of mines and resolve risks through safe developments. This would have farreaching implications for the reduction of major accidents.

\section{Methodology}

\subsection{Preliminary Construction of the Evaluation System}

2.1.1. Dynamic Risk Assessment Process. To prevent the tailings dam breaks and solve for the intervention of humans in early warning systems, an evaluation process is constructed as shown in Figure 1. An initial evaluation index set is established based on the theory of risk management. The early 
TABLE 2: Tailings dam disaster risk identification and indicator evaluation system.

\begin{tabular}{|c|c|c|}
\hline Goals layer & $\begin{array}{l}\text { Guidelines } \\
\text { layer }\end{array}$ & Indicator layer \\
\hline \multirow{23}{*}{$\begin{array}{l}\text { Tailings dam disaster risk } \\
\text { identification } A\end{array}$} & \multirow{8}{*}{$\begin{array}{l}\text { Inherent risk indicators } \\
\qquad B_{1}\end{array}$} & Maximum daily precipitation $C_{1-1}$ \\
\hline & & Seismic capacity of the dam $C_{1-2}$ \\
\hline & & Useful life of the dam $C_{1-3}$ \\
\hline & & Protection of dam surface $C_{1-4}$ \\
\hline & & Severity of tailings dam seepage $C_{1-5}$ \\
\hline & & Dam height $C_{1-6}$ \\
\hline & & Nearby residential buildings $C_{1-7}$ \\
\hline & & Total capacity of the reservoir $C_{1-8}$ \\
\hline & \multirow{15}{*}{$\begin{array}{l}\text { Frequency indicators } \\
\qquad B_{2}\end{array}$} & Surrounding debris flow or landslide conditions $C_{1-9}$ \\
\hline & & Presence or absence of karsts or fracture developments $C_{1-10}$ \\
\hline & & Effect of dam drainage facilities $C_{1-11}$ \\
\hline & & Depth of the immersion line $C_{2-1}$ \\
\hline & & Displacement of the crack $C_{2-2}$ \\
\hline & & Length of the dry beach $C_{2-3}$ \\
\hline & & Dispersion between the top of the beach and the reservoir water level \\
\hline & & $C_{2-4}$ \\
\hline & & Elevation of the beach $C_{2-5}$ \\
\hline & & Elevation of the reservoir water level $C_{2-6}$ \\
\hline & & External ratio $C_{2-7}$ \\
\hline & & Surface horizontal displacement of the dam body $C_{2-8}$ \\
\hline & & Settlement of the surface of the dam body $C_{2-9}$ \\
\hline & & Horizontal displacement inside the dam $C_{2-10}$ \\
\hline & & Settlement inside the dam $C_{2-11}$ \\
\hline
\end{tabular}

warning level for tailings dams is systematically evaluated using Spearman's correlation coefficient, a borda count, and the dynamic AHP and GRA methods. The evaluation method is introduced in Section 2.2.

2.1.2. Evaluation Indicators. Identifying the risk of tailings dam failures requires a multilevel, fuzzy, and complex system. This research characterizes the state of risks to tailings dam to help supervisors obtain information to use during inspections. According to the definitions of risk [30, 31], identifying risks to tailings dams can be divided into inherent risk indicators and frequency indicators. Inherent risk indicators refer mostly to material loss caused, which determines the severity of the consequences of the disaster; they generally refer to the source of the risk. Frequency indicators, which mainly monitor the characteristics of the dams, show the probability that an accident might occur. To choose the most reasonable assessment indicators, this study counted many typical large-scale tailings dam accidents in China and other countries and identified an initial system of indicators, including 22 kinds of dam breakage hazards, as shown in Table 2.

2.1.3. Divide Evaluation Warning Level. The relevant departments of the State Council of the People's Republic of China have drafted an "Emergency Plan for Emergency National Public Emergencies", which standardizes the warning level for emergencies according to their severity and urgency; the risk levels for the safe production of tailings are divided into five levels from high to low. The comment set is described by $\mathrm{V}=$ \{"I warning"; "II warning"; "III warning"; "IV warning"; "V No warning"\} (of which "I warning" is the highest risk level), corresponding risk warning colors in the order red, orange, yellow, blue, and green, and a critical point. These details are shown in Table 3.

The relevant departments of the State Council of the People's Republic of China have drafted an "Emergency Plan for Emergency National Public Emergencies," which standardizes the warning level for emergencies according to their severity and urgency. The risk levels for the safe production of tailings are divided into five levels from high to low. The comment set is described as follows: $\mathrm{V}=\{$ "I warning"; "II warning"; "III warning"; "IV warning"; "V No warning"\} (of which "I warning" is the highest risk level); corresponding risk warning colors in the order red, orange, yellow, blue, and green; and a critical point. The details are shown in Table 3.

\subsection{Calculation of Indicators}

2.2.1. Spearman's Rank Correlation Coefficient. Mining enterprises should use economical, safe, and efficient methods to select the most practical and meaningful early warning identification index from Table 1 . This study selects indicators 
TABLE 3: Elements of critical warning points for each indicator level.

\begin{tabular}{|c|c|c|c|c|c|c|c|c|c|c|c|c|}
\hline$U$ & $u_{1-1}$ & $u_{1-2}$ & $u_{1-3}$ & $u_{1-4}$ & $u_{1-5}$ & $u_{1-6}$ & $u_{2-1}$ & $u_{2-2}$ & $u_{2-3}$ & $u_{2-4}$ & $u_{2-5}$ & $u_{2-6}$ \\
\hline Review data & 95 & 95 & 90 & 85 & 90 & 85 & 95 & 95 & 90 & 85 & 90 & 80 \\
\hline V level (90-100] & 95 & 95 & 95 & 95 & 95 & 95 & 95 & 95 & 95 & 95 & 95 & 95 \\
\hline IV level (80-90] & 85 & 85 & 85 & 85 & 85 & 85 & 85 & 85 & 85 & 85 & 85 & 85 \\
\hline III level (70-80] & 75 & 75 & 75 & 75 & 75 & 75 & 75 & 75 & 75 & 75 & 75 & 75 \\
\hline II level (60-70] & 65 & 65 & 65 & 65 & 65 & 65 & 65 & 65 & 65 & 65 & 65 & 65 \\
\hline I level [0-60] & 55 & 55 & 55 & 55 & 55 & 55 & 55 & 55 & 55 & 55 & 55 & 55 \\
\hline
\end{tabular}

based on Spearman's rank correlation coefficient [32, 33], using the following calculation steps.

Step 1. Spearman's rank correlation coefficient is used to estimate the correlation between two variables $X$ and $Y$, where the correlation between them can be described using a monotonous function. The $\rho$ between the two variables can be +1 or -1 . If the number of elements in the variables $X$ and $Y$ is $N$, the ith value of two random variables is denoted by $X_{i}, Y_{i}$. Sorting the two variables yields two ordered sets of elements $x, y$, where elements $x_{i}, y_{i}$ are the order of $X_{i}$ in $X$ and the order of $Y_{i}$ in $Y$. Spearman's rank correlation coefficient between the random variables $X, Y$ can be calculated from the following:

$$
\rho=1-\frac{6 \sum_{i=1}^{N} d_{i}^{2}}{N\left(N^{2}-1\right)}
$$

where $d_{i}=x_{i}-y_{i},(1 \leq i \leq N)$.

Step 2. The correlation value is selected based on the relevance of the range of results. $|\rho|>0.95$ shows a particularly high correlation; $|\rho| \geq 0.8$ shows a high correlation; $0.5 \leq$ $|\rho|<0.8$ indicates a moderate relationship; $0.3 \leq|\rho|<$ 0.5 indicates a weak relationship; and $|\rho|<0.3$ refers to an extremely weak or irrelevant correlation.

2.2.2. Borda Count. The borda count, also called the borda ordinal method, is used to quantify evaluation elements based on importance $[34,35]$. The basic method is as follows: Let $N$ be the total number of risk factors and $i$ be a certain risk, where $k$ represents a guideline. If $r_{i k}$ represents the level of risk $i$ under criterion $k$, the borda number of $i$ can be calculated as

$$
b_{i}=\sum_{k=1}^{n}\left(N-r_{i k}\right)
$$

\subsubsection{Risk Assessment of the Dynamic Hierarchy-Grey Relation} Analysis Method. The traditional AHP is not enough to evaluate the risk development trend. For example, if the evaluation results of the two tailings dams indicate a state of no warning, it is impossible to further compare which of the two tailings dams is better. This is because the tailings dams can develop in either a benign or a malignant way with the passage of time. Thus, if the current and future state of two tailings dams can be predicted, it will be easy to judge which is safer. For example, if the two risk warning levels of mine No. 1 are "V" and "IV," respectively, while those of mine No. 2 are "V" and "V", respectively, it can be concluded that the latter is safer than the former. Psychology shows that expert evaluators cannot help considering the trend in a mine's warning levels over a certain period of time in the future when making their evaluations. If one expert thinks that mine No. 1 will develop negative way while mine No. 2 will develop in a positive way, it means that mine No. 2 is safer. In other words, traditional evaluation results only represent the present evaluation status, not the future trend [33]. Here, the future state is not meant to be infinite; it is a prediction of the future state for a short period of time and represents the accompanying trend. Therefore, a dynamic analytic hierarchy process (DAHP) would be a more effective way to measure trends in risk. Assessments using DAHP are as follows.

Step 1. Develop the structural hierarchy model, as shown in Table 2. Tailings dam construction evaluation indicators are divided into layers for goals, guidelines, and indicators. There should be a direct link between each target level, the one before, and one after.

Step 2. Construct the dynamic judgment matrix which shows that, for a certain factor in the previous level, like in the traditional AHP, the classic Saaty 1 to 9 scale is still used $[36,37]$. Then, compare the relative importance of the factors related to this level. In the DAHP, the two-factor judgment table $M=\left(\overleftarrow{A_{k}}, \overrightarrow{A_{k}}\right)=\left(\overleftarrow{\delta_{i j}}, \overrightarrow{\delta_{i j}}\right)_{n n}$ is established based on the relationship between $\left(\overleftarrow{A_{k}}, \overrightarrow{A_{k}}\right)$ in layer $A$ and $\left(\overleftarrow{B_{1}}, \overrightarrow{B_{1}}\right),\left(\overleftarrow{B_{2}}, \overrightarrow{B_{2}}\right), \cdots,\left(\overleftarrow{B_{n}}, \overrightarrow{B_{n}}\right)$ in layer $B$. “ऍ” represents the current state of the indicator and " $\longrightarrow$ " represents its future trend after the risk trend is considered. Then create matrix table $M$ as shown in the example below:

$$
\begin{array}{c|cccc}
\left(\overleftarrow{A_{k}}, \overrightarrow{A_{k}}\right) & \left(\overleftarrow{B_{1}}, \overrightarrow{B_{1}}\right) & \left(\overleftarrow{B_{2}}, \overrightarrow{B_{2}}\right) & \ldots & \left(\overleftarrow{B_{n}}, \overrightarrow{B_{n}}\right) \\
\hline\left(\overleftarrow{B_{1}}, \overrightarrow{B_{1}}\right) & \left(\overleftarrow{\delta_{11}}, \overrightarrow{\delta_{11}}\right) & \left(\overleftarrow{\delta_{12}}, \overrightarrow{\delta_{12}}\right) & \ldots & \left(\overleftarrow{\delta_{1 n}}, \overrightarrow{\delta_{1 n}}\right) \\
\left(\overleftarrow{B_{2}}, \overrightarrow{B_{2}}\right) & \left(\overleftarrow{\delta_{21}}, \overrightarrow{\delta_{21}}\right) & \left(\overleftarrow{\delta_{22}}, \overrightarrow{\delta_{22}}\right) & \ldots & \left(\overleftarrow{\delta_{2 n}}, \overrightarrow{\delta_{2 n}}\right) \\
\ldots & \ldots & \ldots & \ldots & \ldots \\
\left(\overleftarrow{B_{n}}, \overrightarrow{B_{n}}\right) & \left(\overleftarrow{\delta_{n 1}}, \overrightarrow{\delta_{n 1}}\right) & \left(\overleftarrow{\delta_{n 2}}, \overrightarrow{\delta_{n 2}}\right) & \ldots & \left(\overleftarrow{\delta_{n n}}, \overrightarrow{\delta_{n n}}\right)
\end{array}
$$

in which $i=1,2, \cdots, n ; j=1,2, \cdots, n$.

Step 3. Use the square root method to calculate the weight vector values of the required evaluation factors because this 
TABLE 4: Average random consistency index R.I.

\begin{tabular}{lcccccccccccc}
\hline$n$ & 2 & 3 & 4 & 5 & 6 & 7 & 8 & 9 & 10 & 11 & 12 & $\cdots$ \\
\hline R.I. & 0 & 0.5149 & 0.8931 & 1.1185 & 1.2494 & 1.3450 & 1.4200 & 1.4616 & 1.4874 & 1.5156 & 1.5405 & $\ldots$ \\
\hline Note: $n$ is the matrix order. & & &
\end{tabular}

facilitates the calculation and determination of its accuracy. The relationship is as follows:

$$
\left(\overleftarrow{w_{i}}, \vec{w}_{i}\right)=\left(\prod_{j=1}^{n}\left(\overleftarrow{\delta_{k j}}, \overrightarrow{\delta_{k j}}\right)\right)^{1 / n}, \quad(i=1,2, \cdots, n)
$$

After the normalization process in (4), use the following equation to find the evaluation factor weight vector $W_{i}$ :

$$
\begin{aligned}
& W=\left(\overleftarrow{W_{i}}, \vec{W}_{i}\right)=\frac{\left(\overleftarrow{w_{i}}, \overrightarrow{w_{i}}\right)}{\sum_{k=1}^{n}\left(\prod_{j=1}^{n}\left(\overleftarrow{\delta_{k j}}, \overrightarrow{\delta_{k j}}\right)\right)}, \\
&(i=1,2, \cdots, n)
\end{aligned}
$$

The weight value obtained from (5) using the DAHP is

$$
W=\left\{\left(\overleftarrow{w}_{1}, \vec{w}_{1}\right),\left(\overleftarrow{w}_{2}, \vec{w}_{2}\right) \ldots\left(\overleftarrow{w}_{n}, \vec{w}_{n}\right)\right\}
$$

Step 4 (perform the judgment matrix consistency test). Using (5), the maximum eigenvalue can be obtained as

$$
\lambda_{\max }=\left(\overleftarrow{\lambda_{\max }}, \overrightarrow{\lambda_{\max }}\right)=\left(\sum_{i=1}^{n} \frac{[A W]_{j}}{n\left(\overleftarrow{w_{i}}, \vec{w}_{i}\right)_{j}}\right)
$$

Then, check the consistency of the judgment matrix as follows:

$$
\text { C.I. }=\frac{\lambda_{\max }-n}{n-1}
$$

Saaty [36] proposed a method by which to amend the C.I. using the mean random coherence index R.I. as shown in Table 4, if C.R. = C.I./R.I. $<0.01$; that is, when C.R. $<$ $0.10, A$ is an acceptable judgment matrix. On the contrary, the initially established matrix is unsatisfactory and needs to be recalculated.

Step 5 (determine the grey relational degree). The GRA determines the desired target for a given state. By analyzing and determining each indicator set, a matrix is formed according to a certain sequence, the grey correlation coefficient can be obtained through a normalization process, and the result can be calculated by combining the determined weight values [38]. Thus, the GRA is used to analyze early warning data for a tailings dam break disaster. The grey correlation coefficient of the tailings dam fault warning, the weight value judged by $\mathrm{AHP}$, and the dynamic alert warning of the degree of the risk of a tailings dam disaster are obtained. Combining a DAHP and GRA is an effective way to measure the alertness of a disaster risk warning system.
First, to make the calculation reasonable based on the average value of the original warning data for the dimensionless treatment, the following matrix $Z_{m \times n}$ is used:

$$
\left[\begin{array}{cccc}
z_{11} & z_{12} & \ldots & z_{1 n} \\
z_{21} & z_{22} & \ldots & z_{2 n} \\
\ldots & \ldots & \ldots & \ldots \\
z_{m 1} & z_{m m} & \ldots & z_{m n}
\end{array}\right]
$$

where $i=1,2, \cdots, m ; j=1,2, \cdots, n$.

Next, the difference sequence between each row is calculated according to (10) below, where $z_{0}(i)$ is the optimal evaluation sample sequence constructed.

$$
\Delta_{i j}=\left|z_{0}(j)-z_{i}(j)\right|
$$

The maximum difference between the poles $\eta$ and minimum difference $u$ is found:

$$
\begin{aligned}
& \eta=\max _{j} \max _{i} \Delta_{i}(j), \\
& u=\min _{j} \min _{i} \Delta_{i}(j)
\end{aligned}
$$

The degree of the correlation coefficient is sought:

$$
\varepsilon_{i j}==\frac{u+\delta \eta}{\Delta_{i j}+\delta \eta}
$$

Given this, the degree of relevance of the sample is as follows:

$$
r_{i}=\left(\overleftarrow{r_{j}}, \vec{r}_{j}\right)=\sum_{i=1}^{m}\left(\overleftarrow{w_{i}}, \vec{w}_{i}\right) \varepsilon_{i j}, \quad(j=1,2, \cdots, n)
$$

where $\delta$ is the resolution coefficient and $\delta \in(0,1)$; here $\delta=0.5,\left(\overleftarrow{w_{i}}, \vec{w}_{i}\right)$ is the normalized weight of the metric set $\left(\overleftarrow{\delta_{i j}}, \overrightarrow{\delta_{i j}}\right)_{n n}(i=1,2, \cdots, n ; j=1,2, \cdots, n)$

\section{Case Study}

3.1. Introduction to the Case Study. The mine used as a case study was originally developed in 1998. The valley-type upstream tailings dam was an impermeable brick dam with an initial elevation of $458.5 \mathrm{~m}$ and a height of $22 \mathrm{~m}$. The tailings yield for a catchment area $1.26 \mathrm{~km}^{2}$ is $80 \%$, and the total dam height designed was $33.5 \mathrm{~m}$ with a total storage capacity of $1.5 \times 10^{6} \mathrm{~m}^{3}$. There were no residential buildings within $2 \mathrm{~km}$ downstream of the dam.

To evaluate the trend in the early warning status, it is necessary to use the expert scoring method to score the evaluation indicators to obtain weight information. However, 
TABLE 5: Spearman's rank correlation coefficient of element $C_{1}$.

\begin{tabular}{lccccc}
\hline Data groups $(N=10)$ & $\begin{array}{c}\text { Maximum daily } \\
\text { precipitation }\end{array}$ & Mean & $\begin{array}{c}\text { Sort rank of element } C_{1} \\
\left(X_{i}\right)\end{array}$ & Average sort rank $\left(Y_{i}\right)$ & $d_{j}^{2}$ \\
\hline$N_{1}$ & 91 & 3.86 & 9 & 5 & 16 \\
$N_{2}$ & 86 & 4.00 & 5 & 6 & 1 \\
$N_{3}$ & 85 & 3.32 & 4 & 3 & 1 \\
$N_{4}$ & 88 & 4.27 & 7 & 10 & 9 \\
$N_{5}$ & 82 & 3.91 & 3 & 4 & 1 \\
$N_{6}$ & 89 & 4.45 & 10 & 8 & 1 \\
$N_{7}$ & 90 & 3.32 & 6 & 9 & 1 \\
$N_{8}$ & 87 & 3.50 & 1 & 7 & 1 \\
$N_{9}$ & 74 & 3.27 & 2 & 2 & 1 \\
$N_{10}$ & 81 & & $\rho=0.76$ & & \\
Correlation coefficient & & & & \\
\hline
\end{tabular}

using a small number of experts would lead to lack of information while too many would lead to information redundancy. Some researchers have analyzed this and verified that it would be optimal to select around 10 people to participate in the evaluation. While evaluating the same subject, different experts have different opinions and give different scores [39] because of their differing levels of education and cultural backgrounds. Experts are also usually of different ages and have different profession positions, work experience, and educational backgrounds; all of this leads to differences in the evaluations [40-42]. Therefore, we invited 10 experts with similar backgrounds to assess the scores of the tailings dam indicators in Table 2. The score results are given in Appendix A.

3.2. Determining the Key Indicators. The 22 categories of indicators are correlated using Spearman's rank correlation coefficient. Taking $C_{1}$ as an example, the third and fourth columns in Table 5 are the rankings of the scores and the mean values of each factor of $C_{1}$, and a correlation coefficient of 0.76 is obtained from (1). The correlation is high; the correlation coefficient results of the other indicators were calculated in a similar manner. For further details, see Appendix B.

Based on the results in Appendix B, the following 12 indicators for early warning evaluation based on their high relevance (a correlation coefficient greater than 0.60) are observed: $C_{1-1}, C_{1-2}, C_{1-5}, C_{1-6}, C_{1-7}, C_{1-8}, C_{2-1}, C_{2-2}, C_{2-3}$, $C_{2-4}, C_{2-9}$, and $C_{2-10}$.

\subsection{Finding the Index Weight}

Step 1. Rename the selected inherent risk indicator $U_{1}$ and frequency indicator $U_{2}$ in sequence, as shown in Table 6.

Step 2. To solve the ambiguity of the results of the comparison between AHP indicator elements, the borda count was used here to quantify the judgments among the indicator elements, and the 12 elements were ranked according to 10 expert scores. Taking the element $U_{1}$ in the inherent risk indicator as an example and using (2), where $N=12$ and $k=10$, its borda ordinal value is obtained as follows:

$$
\begin{aligned}
b_{1}= & (12-1)+(12-7)+(12-2)+(12-7) \\
& +(12-6)+(12-7)+(12-5)+(12-3) \\
& +(12-6)+(12-1)=75
\end{aligned}
$$

Similarly, the borda ordinal values of other elements can be found as shown in Appendix C. The six categories of the inherent risk indicators are $75,74,73,66,58$, and 50 . The six ordinal numbers of the frequency indicators are $93,78,65$, 60,81 , and 75 , and their logarithms are taken in order. The logarithms of the six categories of the inherent risk indicators are $0,1,2,3,4$, and 5 , respectively, while the logarithms of the six categories of the frequency indicators are $0,2,4,5$, 1 , and 3 , respectively. In this matrix, the rows are sorted and added to or subtracted from. The judgment matrix $A$ can be constructed directly and a two-factor judgment matrix $\overleftarrow{u_{k}}$ can be established.

The degree of disaster risk is not equal and policy makers tended to distinguish between them based on risk appetite. Here, the experts scored the risk appetite for the 12 indicator categories using a 10-point score that showed possible future status. The proportion of each factor obtained is shown in Table 7.

The 12 key index scores in Appendix A are multiplied by their respective weights in Table 7 to obtain the reordered matrix as shown in Appendix D. The steps above are repeated, in order, to find the logarithm of the borda ordinal value after considering the risk appetite. The logarithms of the six ordinal numbers for the new inherent risk indicators are 0 , $3,1,4,2$, and 5 , respectively, while the logarithms of the six categories of the new frequency indicators are $0,1,5,2$, 3 , and 4, respectively. Furthermore, there is a row-by-level increase or decrease in the matrix. The judgment matrix can be constructed directly and a two-factor judgment matrix $\overrightarrow{u_{k}}$ can be established. 
TABLE 6: Results of tailings dam evaluation index system weight.

\begin{tabular}{|c|c|c|c|c|c|c|}
\hline \multirow{2}{*}{ Goals layer } & \multirow{2}{*}{$\begin{array}{l}\text { Guidelines Layer } \\
\text { (weight) }\end{array}$} & \multirow{2}{*}{ Indicators layer } & \multicolumn{2}{|c|}{ Current state weight } & \multicolumn{2}{|c|}{ Future state weight } \\
\hline & & & $W_{0}$ & $W_{0}^{\prime}$ & $W_{\mathrm{n}}$ & $W_{\mathrm{n}}^{\prime}$ \\
\hline \multirow{12}{*}{$\begin{array}{l}\text { Tailings dam } \\
\text { disaster risk } \\
\text { identification } U\end{array}$} & \multirow{6}{*}{$\begin{array}{l}\text { Inherent risk } \\
\text { indicators } \\
U_{1}(0.500)\end{array}$} & Maximum daily precipitation $u_{1-1}$ & 0.3825 & 0.1912 & 0.3825 & 0.1912 \\
\hline & & Seismic capacity of the dam $u_{1-2}$ & 0.2504 & 0.1252 & 0.1006 & 0.0503 \\
\hline & & $\begin{array}{l}\text { Severity of tailings dam seepage } \\
\qquad u_{1-3}\end{array}$ & 0.1596 & 0.0798 & 0.2504 & 0.1252 \\
\hline & & Dam height $u_{1-4}$ & 0.1006 & 0.0503 & 0.0641 & 0.032 \\
\hline & & Nearby residential buildings $u_{1-5}$ & 0.0641 & 0.032 & 0.1596 & 0.0798 \\
\hline & & Total capacity of the reservoir $u_{1-6}$ & 0.0428 & 0.0214 & 0.0428 & 0.0214 \\
\hline & \multirow{6}{*}{$\begin{array}{l}\text { Frequency } \\
\text { indicators } \\
U_{2}(0.500)\end{array}$} & Depth of the immersion line $u_{2-1}$ & 0.3813 & 0.1907 & 0.3825 & 0.1912 \\
\hline & & Displacement of the crack $u_{2-2}$ & 0.1584 & 0.0792 & 0.2504 & 0.1252 \\
\hline & & Length of the dry beach $u_{2-3}$ & 0.0636 & 0.0318 & 0.0428 & 0.0214 \\
\hline & & $\begin{array}{l}\text { Dispersion between the top of } \\
\text { the beach and the reservoir water } \\
\text { level } u_{2-4}\end{array}$ & 0.0412 & 0.0206 & 0.1596 & 0.0798 \\
\hline & & $\begin{array}{l}\text { Surface horizontal displacement } \\
\text { of the dam body } u_{2-5}\end{array}$ & 0.2557 & 0.1279 & 0.1006 & 0.0503 \\
\hline & & $\begin{array}{l}\text { Settlement of the surface of the } \\
\text { dam body } u_{2-6}\end{array}$ & 0.0998 & 0.0499 & 0.0641 & 0.032 \\
\hline \multicolumn{2}{|l|}{$\begin{array}{l}\text { Calculation result } \\
\text { (Current state) }\end{array}$} & \multicolumn{5}{|c|}{$\begin{array}{l}\text { Inherent risk consistency ratio: } 0.0194 ; \lambda_{\max }: 6.1225 \\
\text { Frequency risk consistency ratio: } 0.0184 ; \lambda_{\max }: 6.1160\end{array}$} \\
\hline \multicolumn{2}{|l|}{$\begin{array}{l}\text { Calculation result } \\
\text { (Future state) }\end{array}$} & \multicolumn{5}{|c|}{$\begin{array}{l}\text { Inherent risk consistency ratio: } 0.0194 ; \lambda_{\max }: 6.1225 \\
\text { Frequency risk consistency ratio: } 0.0194 ; \lambda_{\max }: 6.1225\end{array}$} \\
\hline
\end{tabular}

Notes: $W_{o}$ is the weight of the original indicator layer to the criteria layer; $W_{o}{ }^{\prime}$ is the weight of the original indicator layer to the target layer; $W_{n}$ is the weight of the new indicator layer on the criteria layer; $W_{n}^{\prime}$ isthe weight of the new indicator layer on the target layer.

The matrix of the inherent risk indicators of the current and possible future states is as follows:

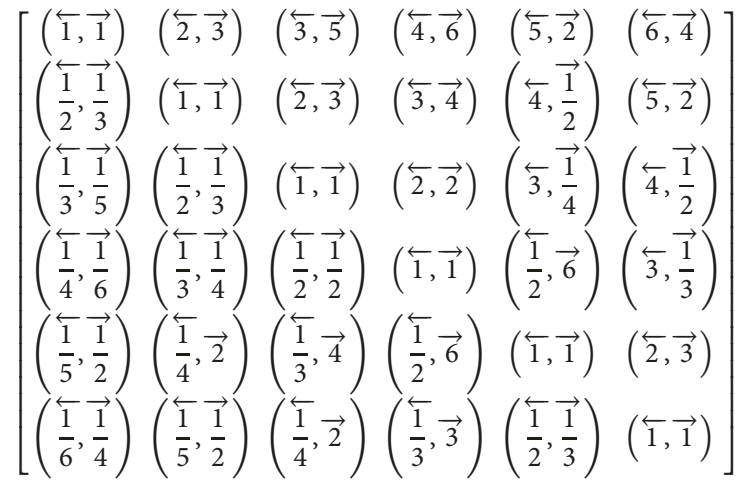

Similarly, the matrix of frequency risk indicators is as follows:

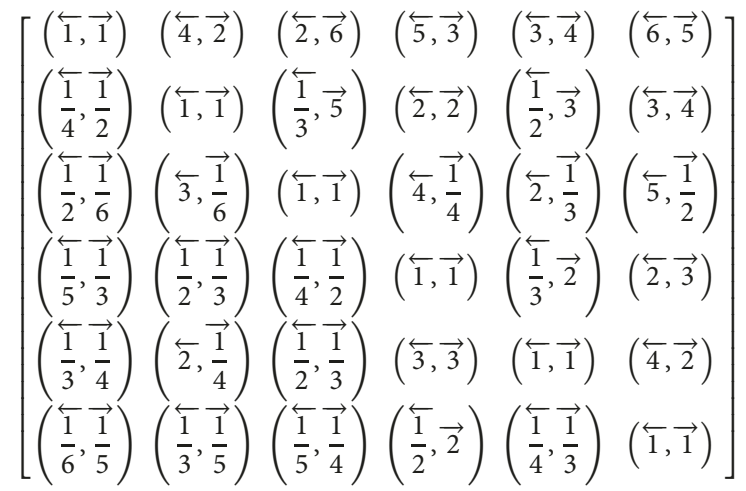

Step 3. Equations (4) and (5) are used to obtain the weights of the two matrices. The maximum eigenvalues are obtained using (7) and verified one at a time using (8), indicating that they are acceptable judgment matrices and satisfactory results. This proves that this method is highly efficient. The final results are shown in Table 6.

3.4. Result Analysis. A correlation assessment matrix is constructed based on the critical early warning points for each element in Table 3 in combination with the selected optimal evaluation reference data. Taking the six "inherent risks" categories as an example, the matrix obtained after dimensionless processing is as follows:

$$
\left[\begin{array}{cccccc}
1 & 1 & 1 & 1 & 1 & 1 \\
1 & 1 & 1.056 & 0.895 & 1.056 & 0.895 \\
0.895 & 0.895 & 0.944 & 1 & 0.944 & 1 \\
0.789 & 0.789 & 0.833 & 0.882 & 0.833 & 0.882 \\
0.648 & 0.648 & 0.722 & 0.765 & 0.722 & 0.765 \\
0.579 & 0.579 & 0.611 & 0.647 & 0.611 & 0.647
\end{array}\right]
$$

The difference between rows and rows are calculated according to (10), and the matrix is reobtained as follows:

$$
\left[\begin{array}{cccccc}
0 & 0 & 0.056 & 0.105 & 0.056 & 0.105 \\
0.105 & 0.105 & 0.056 & 0 & 0.056 & 0 \\
0.211 & 0.211 & 0.167 & 0.118 & 0.167 & 0.118 \\
0.316 & 0.316 & 0.278 & 0.235 & 0.278 & 0.235 \\
0.421 & 0.421 & 0.389 & 0.353 & 0.389 & 0.353
\end{array}\right]
$$


TABLE 7: Proportion of risk preferences for each element.

\begin{tabular}{|c|c|c|c|c|c|c|c|c|c|c|c|c|}
\hline Indicator elements & $u_{1-1}$ & $u_{1-2}$ & $u_{1-3}$ & $u_{1-4}$ & $u_{1-5}$ & $u_{1-6}$ & $u_{2-1}$ & $u_{2-2}$ & $u_{2-3}$ & $u_{2-4}$ & $u_{2-5}$ & $u_{2-6}$ \\
\hline Score & 9 & 6 & 9 & 4 & 8 & 4 & 9 & 9 & 4 & 8 & 7 & 6 \\
\hline Proportion & 0.11 & 0.07 & 0.11 & 0.05 & 0.10 & 0.05 & 0.11 & 0.10 & 0.05 & 0.10 & 0.09 & 0.07 \\
\hline
\end{tabular}

From the above, $\eta=0.421, u=0$; therefore, the available correlation coefficient $\varepsilon_{5 \times 6}$ and the correlation degree can be calculated using (12) and (13), respectively, as follows:

$$
\begin{aligned}
& R_{g u} \\
& =\left[\begin{array}{cccccc}
1 & 1 & 0.790 & 0.667 & 0.790 & 0.667 \\
0.667 & 0.667 & 0.790 & 1 & 0.790 & 1 \\
0.499 & 0.499 & 0.558 & 0.641 & 0.558 & 0.641 \\
0.400 & 0.400 & 0.431 & 0.473 & 0.431 & 0.473 \\
0.333 & 0.333 & 0.351 & 0.374 & 0.351 & 0.374
\end{array}\right]\left[\begin{array}{lll}
0.3825 & 0.3835 \\
0.2504 & 0.1006 \\
0.1596 & 0.2504 \\
0.1006 & 0.0641 \\
0.0641 & 0.1596 \\
0.0428 & 0.0428
\end{array}\right] \\
& =\left[\begin{array}{lllll}
0.9053 & 0.7423 & 0.5326 & 0.4173 & 0.3429 \\
0.8783 & 0.7530 & 0.5384 & 0.4204 & 0.3448
\end{array}\right]^{T}
\end{aligned}
$$

$\overleftarrow{R_{g u(\max )}}=0.9053$ is a Level $\mathrm{V}$ warning and shows a green alert; $\overrightarrow{R_{g u(\max )}}=0.8783$ is a Level IV warning and shows a blue alert. The "frequency risk" degree of relevance is obtained by repeating the above steps in the same way.

$$
\begin{aligned}
& R_{\operatorname{pin}(\max )} \\
& \quad=\left[\begin{array}{lllll}
0.8860 & 0.7532 & 0.5379 & 0.4200 & 0.3448 \\
0.8954 & 0.7591 & 0.5392 & 0.4206 & 0.3448
\end{array}\right]^{T}
\end{aligned}
$$

This shows that "frequency risk" is in the blue alert state.

Using the same method, the overall disaster identification associated with the tailings dam can be obtained as follows:

$$
\begin{aligned}
& \overleftarrow{R} \\
& =\left[\begin{array}{ll}
0.5 & 0.5
\end{array}\right]\left[\begin{array}{lllll}
0.9053 & 0.7423 & 0.5326 & 0.4173 & 0.3429 \\
0.8860 & 0.7532 & 0.5379 & 0.4200 & 0.3445
\end{array}\right] \\
& =\left[\begin{array}{lllll}
0.8957 & 0.7477 & 0.5353 & 0.4186 & 0.3437
\end{array}\right]
\end{aligned}
$$

Similarly, $\vec{R}=\left[\begin{array}{lllll}0.8868 & 0.7560 & 0.5388 & 0.4205 & 0.3448\end{array}\right]$.

This result shows that, based on the optimal reference assessment, both warnings $\overleftarrow{R}$ and $\vec{R}$ are in the blue alert state; however, when the risk bias degree was not considered, $\overleftarrow{R}$ almost approached the "No warning" state. Thus, it is obviously more accurate after the risk degree is considered.

Figure 2 shows clearly that there are two columns for every correlation coefficient. Figure 2 also indicates that the early warning of the two states is almost identical; this is related to the management of the mine. An investigation showed that the mine has a perfect monitoring system for safety development that and no accident occurred in five years.

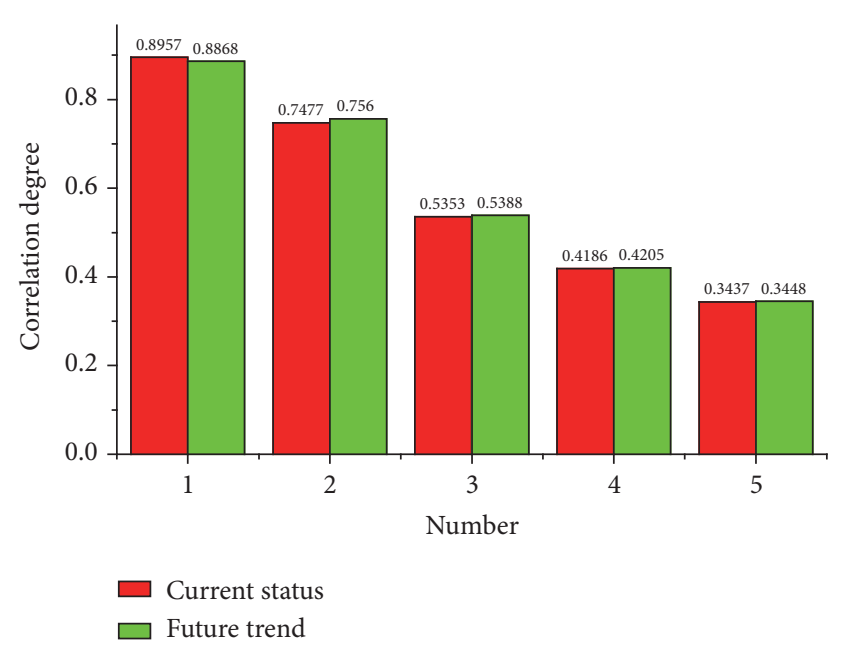

FIGURE 2: Histogram risk evaluation using the DAHP-GAR method.

\section{Results and Discussion}

4.1. Method Comparison Analysis. The analysis of the borda ordinal number results, the characteristic symmetry of AHP, and scale of the latter on the diagonal all have a value of 1 for the purposes of weighing the importance ranking of other indicators. To facilitate a better understanding of this, the advantages of the method are explained in detail by taking the new "inherent risk" using the order in the section on "Finding the index weight" as an example. The relative indicators of the index $u_{1-1}-u_{1-6}$, after sorting by borda ordinals given in the latter section, are $0,3,1,4,2$, and 5 . These are turned into a matrix of diagonal 1 based on the 1-9 scale method and are analyzed as follows.

For the first row of matrix data sources, the index of the first column of the first row of the matrix is scaled to 1. The other values are then added in order of the principle of diagonal 1 and the scale obtained for the first row of the matrix is $1,4,2,5,3$, and 6 .

For the second row of matrix data sources, the index scale of the first row and second column is now 4 , while the scale of the second row and second column of the matrix is still 1. The difference between them is 3 and the scale after the first row will be those values subtracted by 3 . This results in values of $-1,2,0$, and 3; however, according to the order of the scale method, there should be no values equal to 0 or negative numbers. Therefore, these values are converted into $1 / 3$ and $1 / 2$, based on the order of the reciprocal of the scale of 1 to 9 and are finally included on the scale of each element of the second line as follows: $1,1 / 3,2,1 / 2$, and 3 .

An inverted trapezoid with a step edge of 1 is finally obtained using other index scales as analogies. According 
to the principle of symmetry, the reciprocal of each scale constitutes a positive trapezoid with a step edge of 1 in the other half and finally forms a complete conformity with each element. The indicator matrix is as follows:

$$
\left[\begin{array}{cccccc}
1 & 4 & 2 & 5 & 3 & 6 \\
\frac{1}{4} & 1 & \frac{1}{3} & 2 & \frac{1}{2} & 3 \\
\frac{1}{2} & 3 & 1 & 4 & 2 & 5 \\
\frac{1}{5} & \frac{1}{2} & \frac{1}{4} & 1 & \frac{1}{3} & 2 \\
\frac{1}{3} & 2 & \frac{1}{2} & 3 & 1 & 4 \\
\frac{1}{6} & \frac{1}{3} & \frac{1}{5} & \frac{1}{2} & \frac{1}{4} & 1
\end{array}\right]
$$

This borda method, combined with the AHP consistency verification, passes the verification process once; this avoids the trouble of improperly reselected scales.

Using the traditional AHP method results in a high uncertainty. This is because more than one matrix can be established to rank the same importance indexes, as shown in the following two examples:

$$
\left[\begin{array}{cccccc}
1 & 6 & 3 & 7 & 4 & 8 \\
\frac{1}{6} & 1 & \frac{1}{6} & 2 & \frac{1}{3} & 3 \\
\frac{1}{3} & 6 & 1 & 5 & 4 & 7 \\
\frac{1}{7} & \frac{1}{2} & \frac{1}{5} & 1 & \frac{1}{8} & 3 \\
\frac{1}{4} & 3 & \frac{1}{4} & 8 & 1 & 6 \\
\frac{1}{8} & \frac{1}{3} & \frac{1}{7} & \frac{1}{3} & \frac{1}{6} & 1
\end{array}\right]\left[\begin{array}{cccccc}
1 & 6 & 2 & 7 & 3 & 8 \\
\frac{1}{6} & 1 & \frac{1}{5} & 3 & \frac{1}{4} & 6 \\
\frac{1}{2} & 5 & 1 & 3 & 1 & 5 \\
\frac{1}{7} & \frac{1}{3} & \frac{1}{3} & 1 & \frac{1}{2} & 2 \\
\frac{1}{3} & 4 & 1 & 2 & 1 & 2 \\
\frac{1}{8} & \frac{1}{6} & \frac{1}{5} & \frac{1}{2} & \frac{1}{2} & 1
\end{array}\right]
$$

After the traditional subjective judgment method was verified, the two types of consistencies noted above did not meet the requirements. Finding the matrix suitable for this evaluation index using this method was very time-consuming as each possible alternative had to be examined, and even if one passed the verification process it might not have been the only possibility. The method given in this research avoids this problem and achieves a highly efficient, precise, and unique result.

4.2. Comparison of Correlation Coefficients. When the trend of the risk state is not considered, the weight has a great influence on GRA method, which determines the size of the correlation coefficient. For comparison, the traditional AHPGRA method is applied to this case. As with the DAHPGRA method, all evaluation procedures are the same except that the indicators are static. Only the main steps are shown here. Similarly, the inherent risk weight set $W_{1}$ is calculated and frequency risk weight set $W_{2}$ is obtained, after which the corresponding degrees of relevance $R_{1}$ and $R_{2}$ are calculated.

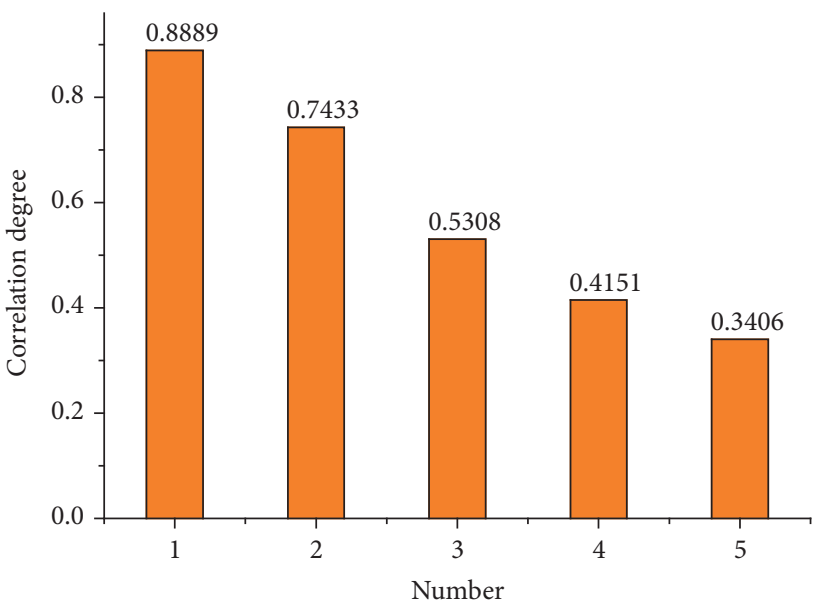

FIgURE 3: Histogram risk evaluation using the conventional AHPGRA method.

Therefore, the correlation degree $R$ of the early warning status of tailings dams can be obtained as follows:

$$
\begin{aligned}
& W_{1} \\
& =\left[\begin{array}{llllll}
0.3412 & 0.2629 & 0.1851 & 0.0963 & 0.0764 & 0.0382
\end{array}\right] \\
& W_{2} \\
& =\left[\begin{array}{llllll}
0.3797 & 0.2542 & 0.0428 & 0.1457 & 0.1140 & 0.0635
\end{array}\right] \\
& R_{1}=\left[\begin{array}{llllll}
0.8804 & 0.7307 & 0.5236 & 0.4100 & 0.3367
\end{array}\right] \\
& R_{2}=\left[\begin{array}{llllll}
0.8973 & 0.7559 & 0.45379 & 0.4201 & 0.3444
\end{array}\right] \\
& R \\
& R=\left[\begin{array}{llllll}
0.5 & 0.5
\end{array}\right]\left[\begin{array}{llllll}
0.8804 & 0.7307 & 0.5236 & 0.4100 & 0.3367 \\
0.8973 & 0.7559 & 0.5379 & 0.4201 & 0.3444
\end{array}\right] \\
& =\left[\begin{array}{llllll}
0.8889 & 0.7433 & 0.5308 & 0.4151 & 0.3406
\end{array}\right]
\end{aligned}
$$

Figure 3 provides a comparison of correlation coefficients for the early warning status of tailings dams. A comparison of Figures 2 and 3 shows that DAHP-GRA method not only avoids the tedious verifications of consistency but also gives the results of future risk trends. The latter can help mine supervisors effectively predict risk trends and find weak links in a timely manner.

4.3. Comparison of Warning Levels. Based on the early warning level set point range for the indicators and given in Table 3, we invited 79 experts to score the element table of the risk of tailings dam breakage. The recovery rate was $100 \%$ and we obtained 79 sets of data as the initial testing sample because the scope of our study was limited and the data group no longer listed. In addition, the results of scoring the 12 key elements selected in Appendix A were listed as test samples (see Table 8). The PNN method was used for early warning analysis [25] and the "newpnn" comprehensive early warning training and test samples were formed. The PNN in the MATLAB neural network toolbox was used to design the 
TABLE 8: Assessment warning results.

\begin{tabular}{lcccccccccccccc}
\hline Data groups & $u_{1-1}$ & $u_{1-2}$ & $u_{1-3}$ & $u_{1-4}$ & $u_{1-5}$ & $u_{1-6}$ & $u_{2-1}$ & $u_{2-2}$ & $u_{2-3}$ & $u_{2-4}$ & $u_{2-5}$ & $u_{2-6}$ & Expert results & PNN results \\
\hline$N_{1}$ & 91 & 87 & 90 & 86 & 88 & 85 & 87 & 83 & 85 & 88 & 88 & 85 & 4 & 4 \\
$N_{2}$ & 86 & 92 & 85 & 91 & 83 & 88 & 95 & 88 & 90 & 83 & 93 & 88 & 4 \\
$N_{3}$ & 85 & 72 & 84 & 71 & 80 & 70 & 75 & 86 & 72 & 82 & 73 & 73 & 3 & 4 \\
$N_{4}$ & 88 & 93 & 87 & 92 & 85 & 91 & 96 & 95 & 93 & 85 & 94 & 94 & 5 & 3 \\
$N_{5}$ & 82 & 85 & 83 & 84 & 81 & 82 & 88 & 84 & 84 & 81 & 86 & 86 & 4 & 5 \\
$N_{6}$ & 89 & 95 & 97 & 96 & 95 & 90 & 92 & 87 & 92 & 95 & 90 & 98 & 5 & 4 \\
$N_{7}$ & 90 & 94 & 89 & 93 & 87 & 89 & 97 & 90 & 91 & 87 & 95 & 95 & 5 & 4 \\
$N_{8}$ & 87 & 84 & 86 & 83 & 84 & 80 & 90 & 91 & 82 & 84 & 85 & 80 & 4 & 5 \\
$N_{9}$ & 74 & 76 & 73 & 75 & 71 & 74 & 79 & 89 & 76 & 71 & 77 & 77 & 3 & 3 \\
$N_{10}$ & 81 & 71 & 80 & 70 & 78 & 69 & 74 & 73 & 71 & 78 & 72 & 72 & 3 & 3 \\
\hline
\end{tabular}

TABLE 9

\begin{tabular}{|c|c|c|c|c|c|c|c|c|c|c|c|c|c|c|c|c|c|c|c|c|c|c|c|}
\hline \multirow{2}{*}{ Data groups } & \multicolumn{23}{|c|}{ Indicator element score results } \\
\hline & $C_{1-1}$ & $C_{1-2}$ & $C_{1-3}$ & $C_{1-4}$ & $C_{1-5}$ & $C_{1-6}$ & $C_{1-7}$ & $C_{1-8}$ & $C_{1-9}$ & $C_{1-10}$ & $C_{1-11}$ & $C_{2-1}$ & $C_{2-2}$ & $C_{2-3}$ & $C_{2-4}$ & $C_{2-5}$ & $C_{2-6}$ & $C_{2-7}$ & $C_{2-8}$ & $C_{2-9}$ & $C_{2-10}$ & $C_{2-11}$ & Mean \\
\hline$N_{1}$ & 91 & 87 & 75 & 71 & 90 & 86 & 88 & 85 & 74 & 79 & 77 & 87 & 83 & 85 & 88 & 87 & 89 & 79 & 88 & 85 & 80 & 77 & 3.86 \\
\hline $\mathrm{N}_{2}$ & 86 & 92 & 82 & 70 & 85 & 91 & 83 & 90 & 71 & 75 & 73 & 95 & 88 & 88 & 83 & 84 & 86 & 86 & 93 & 88 & 74 & 82 & 4.00 \\
\hline$N_{3}$ & 85 & 72 & 89 & 77 & 84 & 71 & 80 & 72 & 80 & 81 & 80 & 75 & 86 & 70 & 82 & 86 & 90 & 90 & 73 & 73 & 79 & 80 & 3.32 \\
\hline$N_{4}$ & 88 & 93 & 90 & 88 & 87 & 92 & 85 & 93 & 85 & 89 & 87 & 96 & 95 & 91 & 85 & 80 & 82 & 98 & 94 & 94 & 88 & 85 & 4.27 \\
\hline$N_{5}$ & 82 & 85 & 67 & 73 & 83 & 84 & 81 & 84 & 76 & 82 & 88 & 88 & 84 & 82 & 81 & 79 & 81 & 88 & 86 & 86 & 81 & 78 & 3.91 \\
\hline$N_{6}$ & 89 & 95 & 71 & 89 & 97 & 96 & 95 & 92 & 79 & 85 & 83 & 92 & 87 & 90 & 95 & 90 & 92 & 75 & 90 & 98 & 84 & 81 & 4.45 \\
\hline$N_{7}$ & 90 & 94 & 88 & 74 & 89 & 93 & 87 & 91 & 77 & 88 & 86 & 97 & 90 & 89 & 87 & 85 & 87 & 92 & 95 & 95 & 87 & 84 & 4.32 \\
\hline$N_{8}$ & 87 & 84 & 96 & 90 & 86 & 83 & 84 & 82 & 73 & 84 & 82 & 90 & 91 & 80 & 84 & 82 & 84 & 80 & 85 & 80 & 82 & 87 & 3.64 \\
\hline$N_{9}$ & 74 & 76 & 91 & 78 & 73 & 75 & 71 & 76 & 64 & 80 & 78 & 79 & 89 & 74 & 71 & 77 & 79 & 95 & 77 & 77 & 78 & 83 & 3.50 \\
\hline$N_{10}$ & 81 & 71 & 77 & 76 & 80 & 70 & 78 & 71 & 75 & 87 & 85 & 74 & 73 & 69 & 78 & 75 & 77 & 81 & 72 & 72 & 85 & 67 & 3.27 \\
\hline
\end{tabular}

function, "wpnn" was used to create the training network, and the sim function was used to simulate the PNN. The parameter spread, with different spread values of 1,6 , and 12 , was divided into three groups of data from which the "for" loops were selected and used to test the performance of the model. The early warning rates were $80 \%$ and above. One of these was selected and the group's early warning classification results are shown in Table 8 . These are almost the same as the warning results assessed by the experts, but the results from the latter were closer to the actual results.

\section{Conclusions}

To identify hazards to tailings dams and prevent human error from affecting the early warning status of these, experiments using the definition of risk were constructed using aspects of intrinsic and frequency risk with which to characterize the safety of the tailing dams. Spearman's rank correlation coefficient method of 22 groups of initial indicators was calculated and 12 key dynamic early warning evaluation indicators were selected. Taking a tailings pond in China as an example, a comprehensive consideration of the risk bias and a study of the DAHP based on borda ordinal number resulted in an improved judgment of fuzzy importance. Those results were also compared with those from the traditional AHP method; it was found that the former avoids a cumbersome verification process and efficiently finding the weight ratios of 12 indicators in combinations of the current and possible future states. It then uses the early warning level and dynamic hierarchical association analysis to predict the "blue" state of early warnings of tailings dam disasters; this allows a better assessment of the state of the tailings dam breach. The method used in this study selects reasonable and effective forecasting indicators for use in mining risk assessments, intelligently updates risk statuses in real time, and establishes a data control and management model based on modern information technology. It would be of great significance in preventing and reducing the occurrence of serious accidents and would also provide a good basis for management inspectors to carry out accurate and realistic monitoring at all levels. We believe that the methods used in this study can also be applied in fields apart from mining safety. However, the early warning assessment data used here were collected from an expert database; other expert databases would need to be updated in real time for this method to be effective. We will also study the sensitivity of tailings dam disaster statuses if the many indicators used in this method that show that the early warning results are on the boundary between safety and danger but have been not studied because of space limits.

\section{Appendix}

\section{A. Expert Rating Results}

See Table 9. 
TABLE 10

\begin{tabular}{|c|c|c|c|c|c|c|c|c|c|c|c|c|c|c|c|c|c|c|c|c|c|c|c|}
\hline \multirow{2}{*}{ Data groups } & \multicolumn{23}{|c|}{ The total sort of index elements } \\
\hline & $C_{1-1}$ & $C_{1-2}$ & $C_{1-3}$ & $C_{1-4}$ & $C_{1-5}$ & $C_{1-6}$ & $C_{1-7}$ & $C_{1-8}$ & $C_{1-9}$ & $C_{1-10}$ & $C_{1-11}$ & $C_{2-1}$ & $C_{2-2}$ & $C_{2-3}$ & $C_{2-4}$ & $C_{2-5}$ & $C_{2-6}$ & $C_{2-7}$ & $C_{2-8}$ & $C_{2-9}$ & $C_{2-10}$ & $C_{2-11}$ & Mean \\
\hline$N_{1}$ & 10 & 6 & 3 & 2 & 9 & 6 & 9 & 6 & 4 & 2 & 4 & 4 & 2 & 6 & 9 & 9 & 8 & 2 & 6 & 5 & 2 & 2 & 5 \\
\hline $\mathrm{N}_{2}$ & 5 & 7 & 5 & 1 & 5 & 7 & 5 & 7 & 2 & 1 & 1 & 8 & 6 & 7 & 5 & 6 & 6 & 5 & 8 & 7 & 1 & 7 & 6 \\
\hline$N_{3}$ & 4 & 2 & 7 & 6 & 4 & 2 & 4 & 2 & 9 & 4 & 3 & 2 & 4 & 2 & 3 & 8 & 9 & 7 & 2 & 3 & 4 & 4 & 3 \\
\hline$N_{4}$ & 7 & 8 & 8 & 8 & 7 & 8 & 7 & 10 & 10 & 10 & 10 & 9 & 10 & 10 & 7 & 4 & 4 & 10 & 9 & 8 & 9 & 10 & 10 \\
\hline$N_{5}$ & 3 & 5 & 1 & 3 & 3 & 5 & 3 & 5 & 6 & 5 & 5 & 5 & 3 & 5 & 4 & 3 & 3 & 6 & 5 & 6 & 10 & 3 & 4 \\
\hline$N_{6}$ & 8 & 10 & 2 & 9 & 10 & 10 & 10 & 9 & 8 & 7 & 7 & 7 & 5 & 9 & 10 & 10 & 10 & 1 & 7 & 10 & 6 & 5 & 8 \\
\hline$N_{7}$ & 9 & 9 & 6 & 4 & 8 & 9 & 8 & 8 & 7 & 9 & 9 & 10 & 8 & 8 & 8 & 7 & 7 & 8 & 10 & 9 & 8 & 6 & 9 \\
\hline$N_{8}$ & 6 & 4 & 10 & 10 & 6 & 4 & 6 & 4 & 3 & 6 & 6 & 6 & 9 & 4 & 6 & 5 & 5 & 3 & 4 & 4 & 5 & 9 & 7 \\
\hline$N_{9}$ & 1 & 3 & 9 & 7 & 1 & 3 & 1 & 3 & 1 & 3 & 2 & 3 & 7 & 3 & 1 & 2 & 2 & 9 & 3 & 2 & 3 & 8 & 2 \\
\hline$N_{10}$ & 2 & 1 & 4 & 5 & 2 & 1 & 2 & 1 & 5 & 8 & 8 & 1 & 1 & 1 & 2 & 1 & 1 & 4 & 1 & 1 & 7 & 1 & 1 \\
\hline
\end{tabular}

TABLE 11

\begin{tabular}{|c|c|c|c|c|c|c|c|c|c|c|c|c|}
\hline \multirow{2}{*}{ Data groups } & \multicolumn{12}{|c|}{ Key element ranking (Current state) } \\
\hline & $u_{1-1}$ & $u_{1-2}$ & $u_{1-3}$ & $u_{1-4}$ & $u_{1-5}$ & $u_{1-6}$ & $u_{2-1}$ & $u_{2-2}$ & $u_{2-3}$ & $u_{2-4}$ & $u_{2-5}$ & $u_{2-6}$ \\
\hline$N_{1}$ & 1 & 4 & 2 & 5 & 3 & 6 & 4 & 7 & 6 & 3 & 3 & 6 \\
\hline $\mathrm{N}_{2}$ & 7 & 3 & 8 & 4 & 9 & 6 & 1 & 6 & 5 & 9 & 2 & 6 \\
\hline$N_{3}$ & 2 & 8 & 3 & 9 & 5 & 10 & 6 & 1 & 8 & 4 & 7 & 7 \\
\hline$N_{4}$ & 7 & 4 & 8 & 5 & 9 & 6 & 1 & 2 & 4 & 9 & 3 & 3 \\
\hline$N_{5}$ & 6 & 3 & 5 & 4 & 7 & 6 & 1 & 4 & 4 & 7 & 2 & 2 \\
\hline$N_{6}$ & 7 & 4 & 2 & 3 & 4 & 6 & 5 & 8 & 5 & 4 & 6 & 1 \\
\hline$N_{7}$ & 5 & 3 & 6 & 4 & 7 & 6 & 1 & 5 & 4 & 7 & 2 & 2 \\
\hline$N_{8}$ & 3 & 6 & 4 & 7 & 6 & 9 & 2 & 1 & 8 & 6 & 5 & 9 \\
\hline$N_{9}$ & 6 & 4 & 7 & 5 & 8 & 6 & 2 & 1 & 4 & 8 & 3 & 3 \\
\hline$N_{10}$ & 1 & 7 & 2 & 8 & 3 & 9 & 4 & 5 & 7 & 3 & 6 & 6 \\
\hline Original borda ordinal & 75 & 74 & 73 & 66 & 58 & 50 & 93 & 78 & 65 & 60 & 81 & 75 \\
\hline
\end{tabular}

TABLE 12

\begin{tabular}{|c|c|c|c|c|c|c|c|c|c|c|c|c|}
\hline \multirow{2}{*}{ Data groups } & \multicolumn{12}{|c|}{ Key element ranking (Future trend) } \\
\hline & $u_{1-1}$ & $u_{1-2}$ & $u_{1-3}$ & $u_{1-4}$ & $u_{1-5}$ & $u_{1-6}$ & $u_{2-1}$ & $u_{2-2}$ & $u_{2-3}$ & $u_{2-4}$ & $u_{2-5}$ & $u_{2-6}$ \\
\hline$N_{1}$ & 1 & 7 & 2 & 8 & 4 & 9 & 3 & 5 & 9 & 4 & 6 & 7 \\
\hline$N_{2}$ & 2 & 7 & 3 & 9 & 6 & 11 & 1 & 4 & 10 & 6 & 5 & 8 \\
\hline$N_{3}$ & 1 & 9 & 2 & 11 & 6 & 12 & 4 & 3 & 10 & 5 & 7 & 8 \\
\hline$N_{4}$ & 2 & 8 & 3 & 10 & 5 & 11 & 1 & 4 & 9 & 5 & 6 & 7 \\
\hline$N_{5}$ & 3 & 8 & 2 & 9 & 5 & 10 & 1 & 4 & 9 & 5 & 6 & 7 \\
\hline$N_{6}$ & 3 & 8 & 1 & 9 & 4 & 11 & 2 & 5 & 10 & 4 & 6 & 7 \\
\hline$N_{7}$ & 2 & 8 & 3 & 10 & 5 & 12 & 1 & 4 & 9 & 5 & 6 & 7 \\
\hline$N_{8}$ & 2 & 7 & 3 & 9 & 5 & 11 & 1 & 4 & 10 & 5 & 6 & 8 \\
\hline$N_{9}$ & 3 & 8 & 4 & 10 & 5 & 11 & 2 & 1 & 9 & 5 & 6 & 7 \\
\hline$N_{10}$ & 1 & 8 & 2 & 10 & 4 & 11 & 3 & 5 & 9 & 4 & 6 & 7 \\
\hline New borda ordinal & 100 & 42 & 95 & 25 & 51 & 11 & 101 & 81 & 26 & 72 & 60 & 47 \\
\hline
\end{tabular}

\section{B. Spearman's Rank Correlation Coefficient Results}

See Table 10.

\section{Key Element Original Borda Ordinal}

See Table 11.

\section{Key Elements New Borda Ordinal}

See Table 12.

\section{Data Availability}

The data used to support the findings of this study are available from the corresponding author upon request. 


\section{Conflicts of Interest}

The authors declare no conflicts of interest.

\section{Acknowledgments}

This work was supported by the National Key Technology Project of Prevention and Control of Major Accidents in Safety Production (Grant no. 149hubei-0002-2017AQ).

\section{References}

[1] F. Hooshyaripor, A. Tahershamsi, and S. Razi, "Dam break flood wave under different reservoir's capacities and lengths," Sädhanā, vol. 42, no. 9, pp. 1557-1569, 2017.

[2] A. B. Fourie, G. E. Blight, and G. Papageorgiou, "Static liquefaction as a possible explanation for the merriespruit tailings dam failure," Canadian Geotechnical Journal, vol. 38, no. 4, pp. 707719, 2001.

[3] B. Wang, C. Wu, L. Huang, L. Zhang, L. Kang, and K. Gao, "Prevention and control of major accidents (MAs) and particularly serious accidents (PSAs) in the industrial domain in China: current status, recent efforts and future prospects," Process Safety and Environmental Protection, vol. 117, pp. 254266, 2018.

[4] R. J. J. Beerens and H. Tehler, "Scoping the field of disaster exercise evaluation - a literature overview and analysis," International Journal of Disaster Risk Reduction, vol. 19, pp. 413-446, 2016.

[5] Y. Sui, R. Ding, and H. Wang, "An integrated management system for occupational health and safety and environment in an operating nuclear power plant in East China and its management information system," Journal of Cleaner Production, vol. 183, pp. 261-271, 2018.

[6] P. Baybutt, "Issues for security risk assessment in the process industries," Journal of Loss Prevention in the Process Industries, vol. 49, pp. 509-518, 2017.

[7] O. Uduma, M. Galligan, H. Mollel, H. Masanja, S. Bradley, and E. McAuliffe, "The impact of a human resource management intervention on the capacity of supervisors to support and supervise their staff at health facility level," Human Resources for Health, vol. 15, p. 57, 2017.

[8] Z. Z. Wu and G. D. Mei, "Statistical analysis of tailings pond accidents and cause analysis of dam failure," China Safety Science Journal, vol. 24, no. 9, pp. 71-76, 2014 (Chinese).

[9] N. Khakzad, F. Khan, P. Amyotte, and V. Cozzani, "Risk management of domino effects considering dynamic consequence analysis," Risk Analysis, vol. 34, no. 6, pp. 1128-1138, 2014.

[10] K. Wernstedt and P. Murray-Tuite, “The dynamic nature of risk perceptions after a fatal transit accident," Risk Analysis, vol. 35, no. 3, pp. 536-552, 2015.

[11] S. Di Zio and M. Maretti, "Acceptability of energy sources using an integration of the Delphi method and the analytic hierarchy process," Quality \& Quantity, vol. 48, no. 6, pp. 2973-2991, 2014.

[12] S. Xu, T. Wang, and S. Hu, "Dynamic assessment of water quality based on a variable fuzzy pattern recognition model," International Journal of Environmental Research and Public Health, vol. 12, no. 2, pp. 2230-2248, 2015.

[13] D. Güler and T. Yomralığlu, "Alternative suitable landfill site selection using analytic hierarchy process and geographic information systems: a case study in Istanbul," Environmental Earth Sciences, vol. 76, no. 20, pp. 1866-6280, 2017.

[14] E. Thanassoulis, P. K. Dey, K. Petridis, I. Goniadis, and A. C. Georgiou, "Evaluating higher education teaching performance using combined analytic hierarchy process and data envelopment analysis," Journal of the Operational Research Society, vol. 68, no. 4, pp. 431-445, 2017.

[15] H. Wei, M. Wang, B. Song, X. Wang, and D. Chen, "Study on the magnitude of reservoir-triggered earthquake based on support vector machines," Complexity, vol. 2018, Article ID 2830690, 10 pages, 2018.

[16] K. Hou, X. Li, J. Wang, and J. Zhang, "Evaluating ecological vulnerability using the GIS and analytic hierarchy process (AHP) method in Yan'an, China," Polish Journal of Environmental Studies, vol. 25, no. 2, pp. 599-605, 2016.

[17] A. Samvedi, V. Jain, and F. T. Chan, "An integrated approach for machine tool selection using fuzzy analytical hierarchy process and grey relational analysis," International Journal of Production Research, vol. 50, no. 12, pp. 3211-3221, 2012.

[18] X. Xia, Y. Sun, K. Wu, and Q. Jiang, "Optimization of a straw ring-die briquetting process combined analytic hierarchy process and grey correlation analysis method," Fuel Processing Technology, vol. 152, pp. 303-309, 2016.

[19] D. Mathivathanan, K. Govindan, and A. N. Haq, "Exploring the impact of dynamic capabilities on sustainable supply chain firm's performance using grey-analytical hierarchy process," Journal of Cleaner Production, vol. 147, pp. 637-653, 2017.

[20] Q. F. Nian, S. L. Shi, R. Q. Li, and W. K. Luo, "Research on risk early warning of safety production based on PNN in coal mines," Journal of Safety Science and Technology, vol. 20, no. 7, pp. 1345-1359, 2013.

[21] D.-X. Zhao, B.-J. He, C. Johnson, and B. Mou, "Social problems of green buildings: from the humanistic needs to social acceptance," Renewable \& Sustainable Energy Reviews, vol. 51, pp. 1594-1609, 2015.

[22] A. T. Ubando, J. L. Cuello, M. M. El-Halwagi, A. B. Culaba, M. A. B. Promentilla, and R. R. Tan, "Application of stochastic analytic hierarchy process for evaluating algal cultivation systems for sustainable biofuel production," Clean Technologies and Environmental Policy, vol. 18, no. 5, pp. 1281-1294, 2016.

[23] R. Biloslavo and A. Grebenc, "Integrating group Delphi, analytic hierarchy process and dynamic fuzzy cognitive maps for a climate warning scenario," Kybernetes, vol. 41, no. 3-4, pp. 414428, 2012.

[24] M. Hadzikadic, T. Carmichael, and C. Curtin, "Complex adaptive systems and game theory: an unlikely union," Complexity, vol. 16, no. 1, pp. 34-42, 2010.

[25] Y. Gu, Z. Bao, and Z. Rui, "Complex lithofacies identification using improved probabilistic neural networks," Petrophysics, vol. 59, no. 2, pp. 245-267, 2018.

[26] D. E. Goldberg, K. Sastry, and X. Llora, “Toward routine billionvariable optimization using genetic algorithms," Complexity, vol. 12, no. 3, pp. 27-29, 2007.

[27] D. Lin, C. K. M. Lee, and Z. Wu, "Integrating analytical hierarchy process to genetic algorithm for re-entrant flow shop scheduling problem," International Journal of Production Research, vol. 50, no. 7, pp. 1813-1824, 2012.

[28] R. G. van der Vegt, "Risk assessment and risk governance of liquefied natural gas development in gladstone, Australia," Risk Analysis, vol. 38, no. 9, pp. 1830-1846, 2018. 
[29] M. Abimbola and F. Khan, "Dynamic blowout risk analysis using loss functions," Risk Analysis, vol. 38, no. 2, pp. 255-271, 2018.

[30] B. He, D. Zhao, J. Zhu, A. Darko, and Z. Gou, "Promoting and implementing urban sustainability in China: an integration of sustainable initiatives at different urban scales," Habitat International, vol. 82, pp. 83-93, 2018.

[31] A. Meel and W. D. Seider, "Real-time risk analysis of safety systems," Computers \& Chemical Engineering, vol. 32, no. 4-5, pp. 827-840, 2008.

[32] C. Spearman, "The proof and measurement of association between two things," International Journal of Epidemiology, vol. 39, no. 5, pp. 1137-1150, 2010.

[33] L. Yan, L. Zhang, W. Liang, W. Li, and M. Du, "Key factors identification and dynamic fuzzy assessment of health, safety and environment performance in petroleum enterprises," Safety Science, vol. 94, pp. 77-84, 2017.

[34] P. Emerson, "The original Borda count and partial voting," Social Choice and Welfare, vol. 40, no. 2, pp. 353-358, 2013.

[35] C. John, H. Hsiao, and P. David, "A Borda count for partially ordered ballots," Social Choice and Welfare, vol. 42, no. 4, pp. 913-926, 2014.

[36] T. L. Saaty, "A scaling method for priorities in hierarchical structures," Journal of Mathematical Psychology, vol. 15, no. 3, pp. 234-281, 1977.

[37] E. Kazuva, J. Zhang, Z. Tong, A. Si, and L. Na, “The DPSIR model for environmental risk assessment of municipal solid waste in Dar es Salaam city, Tanzania," International Journal of Environmental Research and Public Health, vol. 15, no. 8, pp. 1660-4601, 2018.

[38] G. Zeng, R. Jiang, G. Huang, M. Xu, and J. Li, “Optimization of wastewater treatment alternative selection by hierarchy grey relational analysis," Journal of Environmental Management, vol. 82, no. 2, pp. 250-259, 2007.

[39] W. Li, W. Liang, L. Zhang, and Q. Tang, "Performance assessment system of health, safety and environment based on experts' weights and fuzzy comprehensive evaluation," Journal of Loss Prevention in the Process Industries, vol. 35, pp. 95-103, 2015.

[40] M. Yazdi, F. Nikfar, and M. Nasrabadi, "Failure probability analysis by employing fuzzy fault tree analysis," International Journal of Systems Assurance Engineering and Management, vol. 8, pp. 1177-1193, 2017.

[41] A. Mottahedi and M. Ataei, "Fuzzy fault tree analysis for coal burst occurrence probability in underground coal mining," Tunnelling and Underground Space Technology, vol. 83, pp. 165174, 2019.

[42] S. M. Lavasani, N. Ramzali, F. Sabzalipour, and E. Akyuz, "Utilisation of fuzzy fault tree analysis (FFTA) for quantified risk analysis of leakage in abandoned oil and natural-gas wells," Ocean Engineering, vol. 108, pp. 729-737, 2015. 


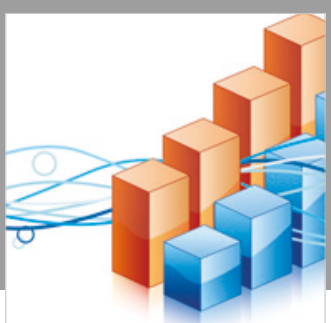

Advances in

Operations Research

\section{-n-m}
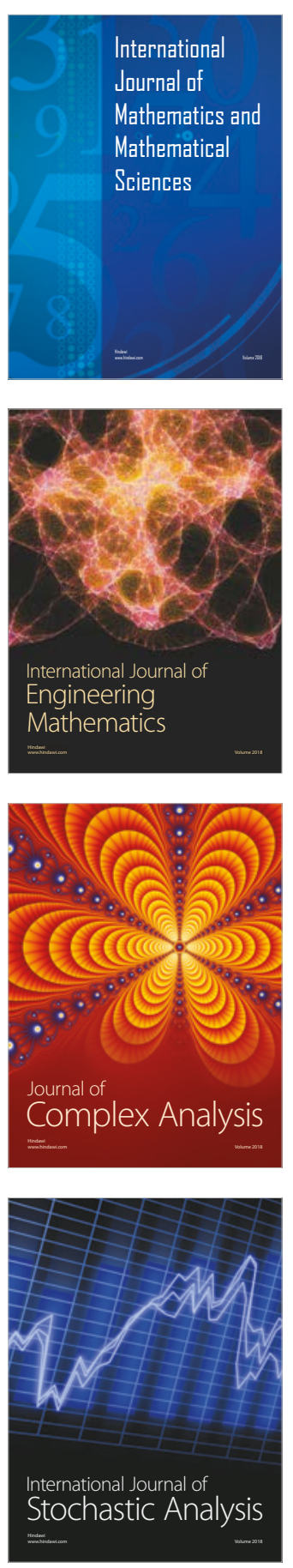
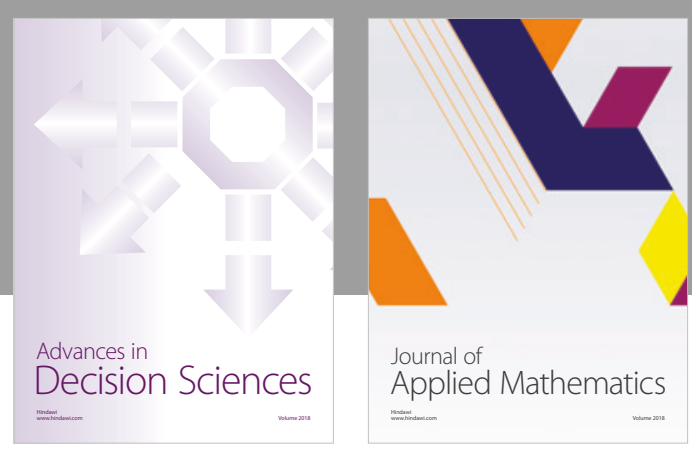

Journal of

Applied Mathematics
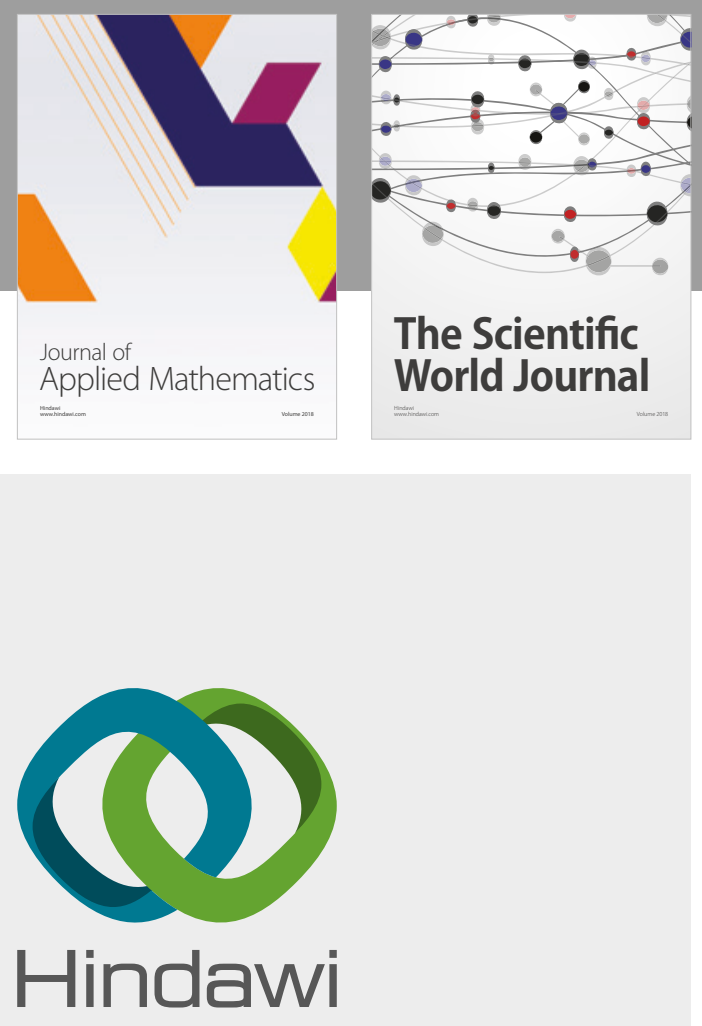

Submit your manuscripts at

www.hindawi.com

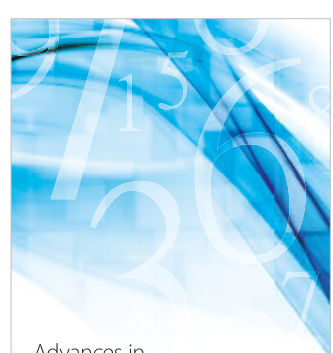

Advances in
Numerical Analysis
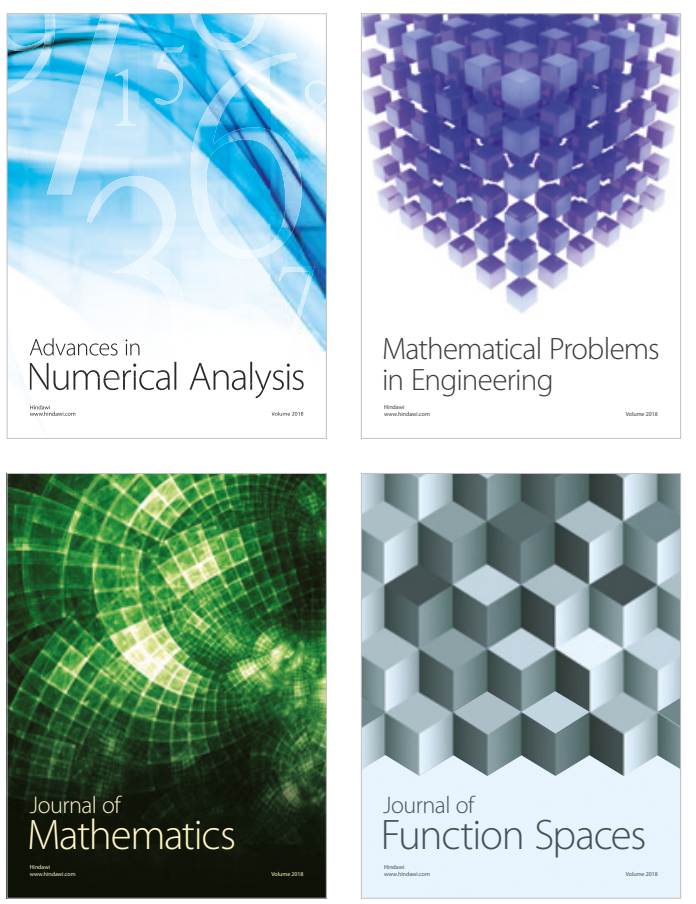

Mathematical Problems in Engineering

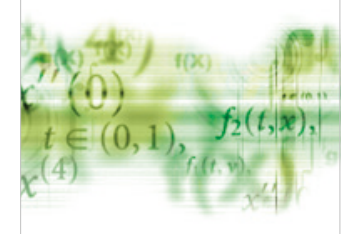

International Journal of

Differential Equations

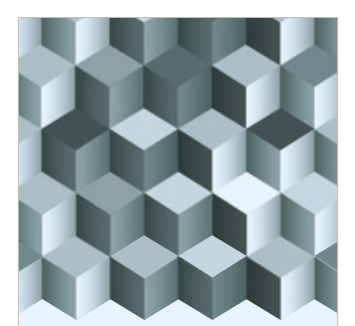

Journal of

Function Spaces
The Scientific

World Journal

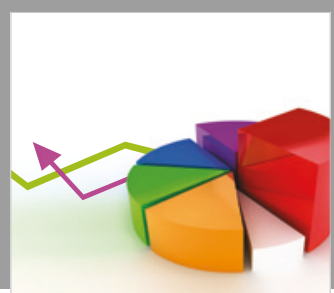

Journal of

Probability and Statistics
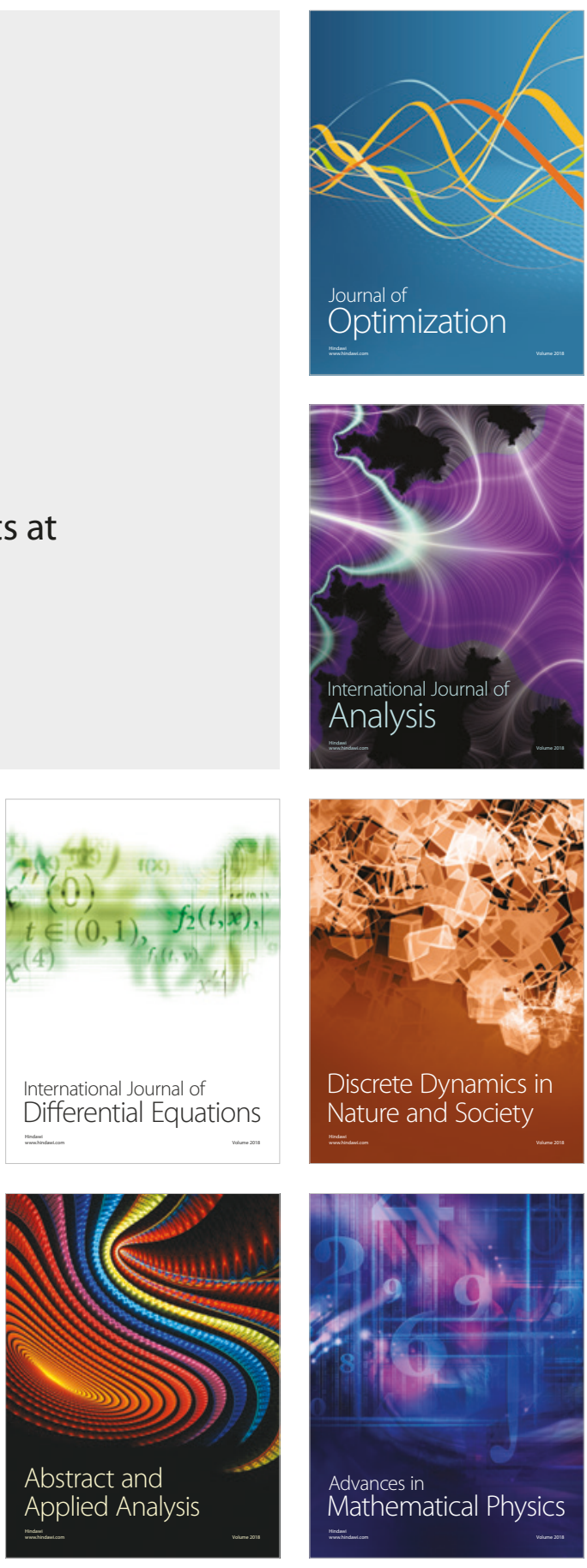